\title{
Delayed rise in incidence of gastric cancer in females results in unique sex ratio (M/F) pattern: etiologic hypothesis
}

\author{
Pentti Sipponen $^{1}$ and Pelayo Correa ${ }^{2}$ \\ ${ }^{1}$ Department of Pathology, HUCH-Jorvi Hospital, 02740 Espoo, Finland \\ ${ }^{2}$ Department of Pathology, LSU Medical Center, New Orleans, LA, USA
}

\begin{abstract}
Background. The age-standardized and cumulative incidence rates of gastric cancer (GCA) are twice as high in males as in females.

Methods. Based on age-group-specific (5-year age groups) annual incidence data of GCA among males and females published by 18 cancer registries worldwide, and on a consecutive series of 938 GCAs from Finland, we explored how the male predominance of GCA has changed over the decades and how this male predominance may possibly vary worldwide between populations with high and low gastric cancer incidence.

Results. It appeared that the age-group-specific male-tofemale (M/F) ratio of the annual GCA incidence is not constant but increases with age, reaches a peak at age around 60, and decreases thereafter. This special form of the $M / F$ curve is not seen in other gastrointestinal (GI) cancer types (colon, rectum, pancreas). This "low-high-low" form of the M/F curve is related to a 10- to 15-year delay in the appearance and onset of GCA of the intestinal type in females compared with males. The age-group-specific $\mathrm{M} / \mathrm{F}$ ratio rises as the GCA of the intestinal subtype prevails in males and is rare in females before age 60 and starts to decrease after age 60 as the GCA of the intestinal subtype begins to be common also in females. This special form of the $M / F$ curve is globally consistent and similar in countries or populations of high and low GCA incidence. The data from the Finnish Cancer Registry indicate that the age group-specific M/F curve of the annual GCA incidence has, in addition, remained unchanged over the decades (from the 1950s) in spite of a decrease in the annual GCA incidence of more than $70 \%$. In order to examine the role of gastritis-related diseases as a cause of the sex difference in GCA, 1700 consecutive endoscopied outpatients were studied in Finland. In this series, the age-group-specific prevalences of Helicobacter pylori gastritis, atrophic gastritis, or intestinal metaplasia were proportionally as common in males as in females in all age groups except for the youngest one (20-49 years), in which $\boldsymbol{H}$. pylori nonatrophic gastritis was slightly more common in males than in females.
\end{abstract}

Offprint requests to: $\mathrm{P}$. Sipponen

Received: March 18, 2002 / Accepted: August 6, 2002
Conclusion. The male predominance of GCA is a global phenomenon, and is similar in populations with high and low GCA incidence, and this predominance is related to a 10- to 15-year delay in the appearance and onset of GCA of the intestinal subtype in females compared with males. It is suggested that sex hormones (estrogens) protect women against GCA, and that GCA begins to be as prevalent in females as in males only after the menopausal age. Another possibility is that a later acquisition of $\boldsymbol{H}$. pylori gastritis in females than in males causes the relative delay in the appearance and onset of new GCA cases in females compared with males.

Key words Gastric cancer · Estrogens - Trefoil factor • H. pylori

\section{Introduction}

Age-standardized and cumulative incidence rates of gastric cancer (GCA) in males are approximately double those in females. For example, the annual agestandardized (world population 1982-1986) incidence rates in Cali, Colombia, were 36.3 per 100000 males and 19.9 per 100000 females; the cumulative rates being 4.45 and 2.36 respectively, for age up to 74 years [1]. In Finland, the corresponding age-standardized rates were 20.3 for males and 11.2 for females, and the cumulative rates were 2.27 and 1.17 , respectively [1]. The sex ratio of the incidence rates varies, however, with age, forming a "low-high-low" pattern, which seems to be unique to stomach cancer [1].

It is postulated that the specific pattern in the $\mathrm{M} / \mathrm{F}$ ratio of the annual GCA incidence is related to a dissimilar timing in the appearance (incidence) of new GCA cases between males and females. This hypothesis was tested by studying the statistics on GCA published by cancer registries and the International Agency for Research on Cancer (IARC) world-wide, the results of which are presented in this report. 
The etiology of GCA is considered to be multifactorial. It has been recognized by the IARC that infection with Helicobacter pylori plays a causal role [2]. Therefore, the possible etiologic implications of $H$. pylori gastritis and sex hormones on the differences of GCA between males and females are also discussed.

\section{Subjects and methods}

Data on the annual incidence of GCA were obtained from the IARC publication Cancer in five continents, Vol. VI [1]. Additionally, statistics for Finland over the decades (1955-1990) were obtained from the official publications of the Finnish Cancer Registry [3,4]. Data on cancer incidences were accepted and analyzed in the present study only from registries from which there were more than 500 observations during the recording period.

The age-group-specific annual incidence rates of different subtypes of GCA (intestinal, diffuse, unclassified) for Finland were obtained by applying the proportions of the GCA subtypes in different age groups in a series of 938 consecutive cancer cases (Table 1), including all those diagnosed by endoscopy, surgery, and/or autopsy at the Helsinki District University Central Hospital (HUCH)-Jorvi Hospital, Espoo, Finland. The HUCH-Jorvi Hospital, represents the population of Finland, especially the urban south of the country. The histologic classification was based on the criteria of Laurén [5].

The age-group-specific prevalences of chronic gastritis and atrophic gastritis in males and females were examined by a cross-sectional survey of 1700 consecutive outpatients endoscopied at HUCH-Jorvi Hospital for dyspeptic symptoms in 1986-1991. In all, at least two biopsies from antrum and corpus were available and analyzed.

\section{Incidence and incidence rate}

The terms "age-group-specific incidence" and "incidence rate" are used in the present study. They refer to the number of new cancer cases diagnosed annually in a standardized population (per 100000 males or females) in different age groups (5-year age groups) as expressed in the official publications of the cancer registries and IARC.

\section{Results}

The male-to-female ratio ( $\mathrm{M} / \mathrm{F}$ ratio) of the annual incidence rates of GCA in different age groups for eight 5year time periods (1955 to 1990) in Finland is depicted

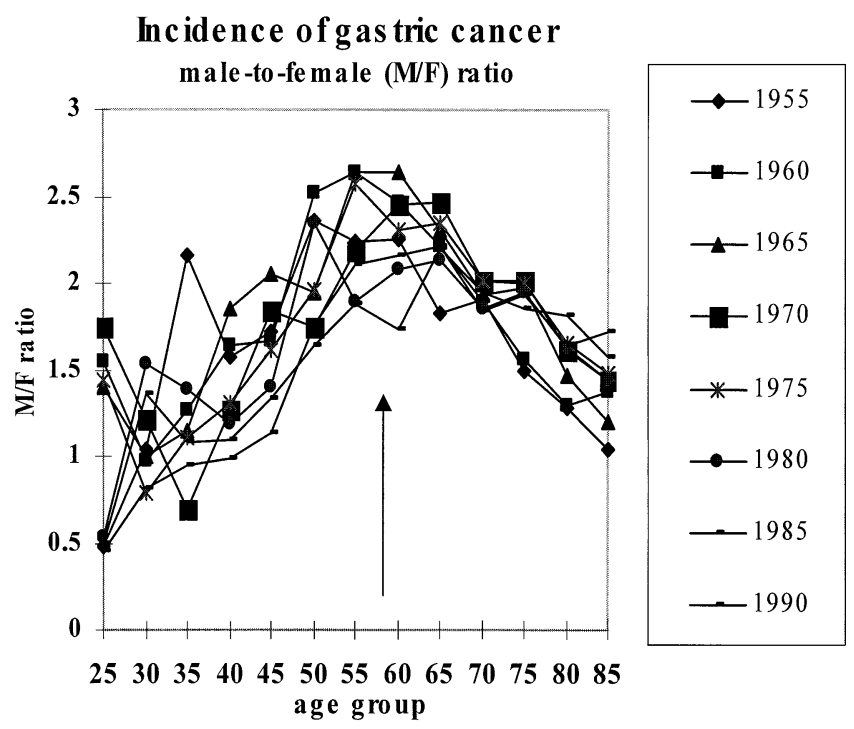

Fig. 1. The "low-high-low" form of the curve of the the maleto-female $(M / F)$ ratio of the annual incidence of gastric cancer in 5-year age groups. Data of the Finnish Cancer Registry from different time periods (1955-1990). The arrow indicates the age of the highest $\mathrm{M} / \mathrm{F}$ ratio

in Fig. 1 . The ratio is approximately 1 in young age groups (20-39 years) but rises thereafter and reaches a peak of 2 to 2.5 in age groups around 60 , after which it decreases and reaches levels only slightly higher (around 1.5) than those observed in young age groups. This special "low-high-low" form of the M/F curve over the age groups was constantly observed and was similar (Fig. 1) at all chronologic time periods (from the 1950s to the 1990s), even though the age-adjusted incidence of gastric cancer in Finland had decreased by $77 \%$ in males and $76 \%$ in females from 1953 to 1995 [4].

The age-group-specific M/F ratios of the annual GCA incidence in populations (countries) with high, intermediate, or low incidence, published in Cancer in five continents. Vol VI [1], are shown in Fig. 2. Again, the special "low-high-low" form of the $\mathrm{M} / \mathrm{F}$ curve is observed, with ratios close to 1 in young age groups, close to 2.5 around age 60 , and 1.5 to 2 in old age groups. Furthermore, a similar form of the M/F ratio was also observed when the incidence rates of GCA in different birth cohorts from Finland were looked at (data not shown). Such patterns are not found for other cancers, as shown for colon and pancreas cancers in Figs. 3 and 4.

In order to examine differences in the GCA incidence between males and females more closely, we explored more deeply the data published by the Finnish Cancer Registry in 1986. The age-group-specific annual incidence rates for all GCAs in males and females in 1986 are shown in Fig. 5 and those for the intestinal and diffuse types in Fig. 6. These latter incidence rates were derived by calculation of the proportions of GCAs of 


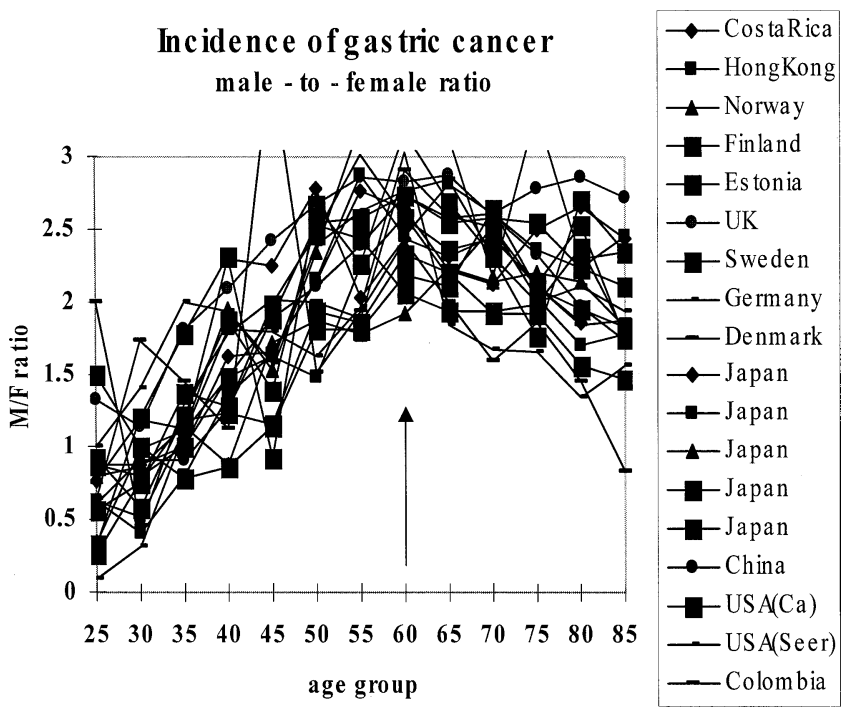

Fig. 2. The age-group-specific $M / F$ ratios of the annual gastric cancer incidence from 18 cancer registries representing countries with low, intermediate, and high cancer incidence during the time period 1986-1990. The arrow indicates the age of the highest $\mathrm{M} / \mathrm{F}$ ratio

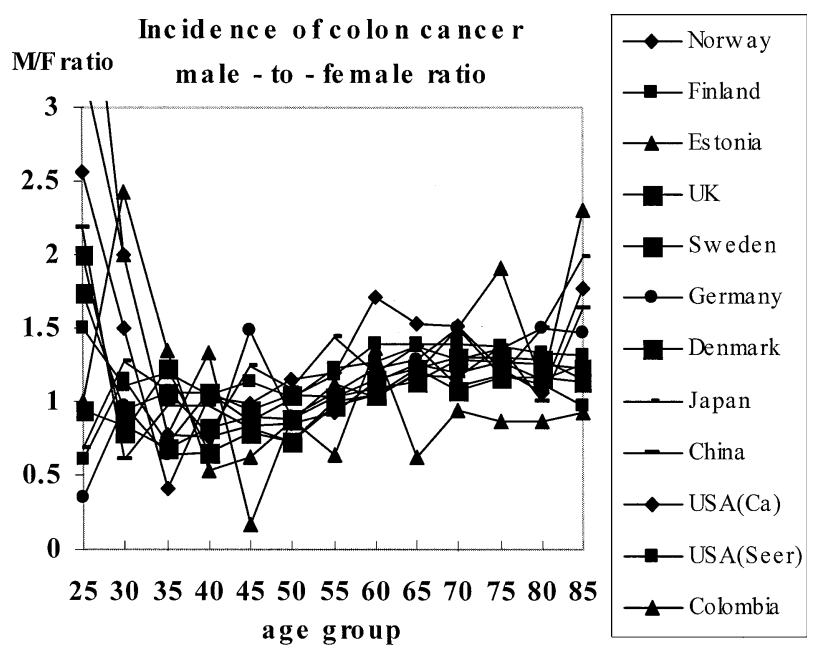

Fig. 3. The age-group-specific $\mathrm{M} / \mathrm{F}$ ratios of the annual colon cancer incidence from 12 cancer registries with more than 500 observations (years 1986-1990)

the intestinal and diffuse subtypes in different 5-year age groups in a consecutive series of 938 stomach cancers (Table 1) from Southern Finland in 1976-1995 and by applying these proportions to the cancer incidence data from Finland in 1986. It appears that the "low-high-low" pattern of the M/F ratio for GCA is related to differences in age-group-specific incidences of GCA between males and females, particularly with those of the intestinal type. GCA of the intestinal subtype seems to appear 10 to 15 years earlier in men than in women, and GCA of the intestinal subtype is rare in

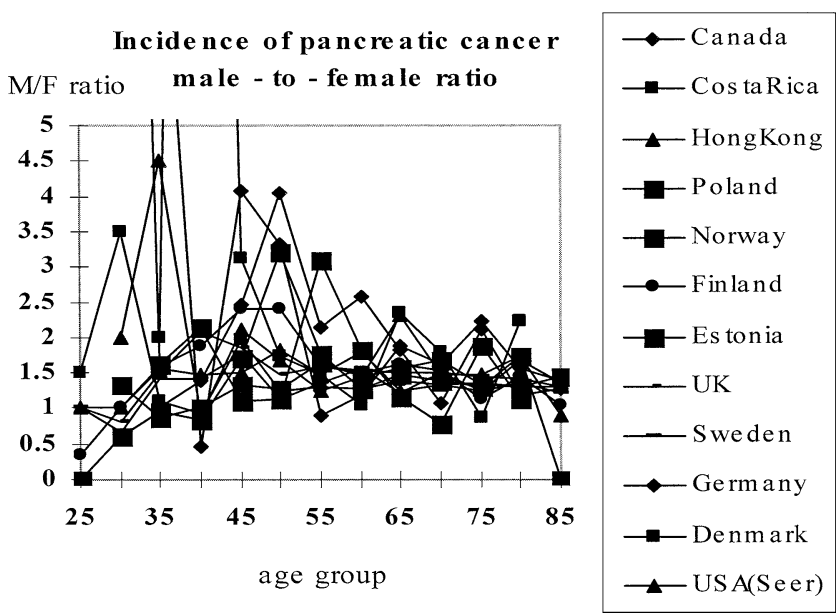

Fig. 4. The age-group-specific $M / F$ ratios of the annual pancreatic cancer incidence from 12 cancer registries with more than 100 observations (years 1986-1990)

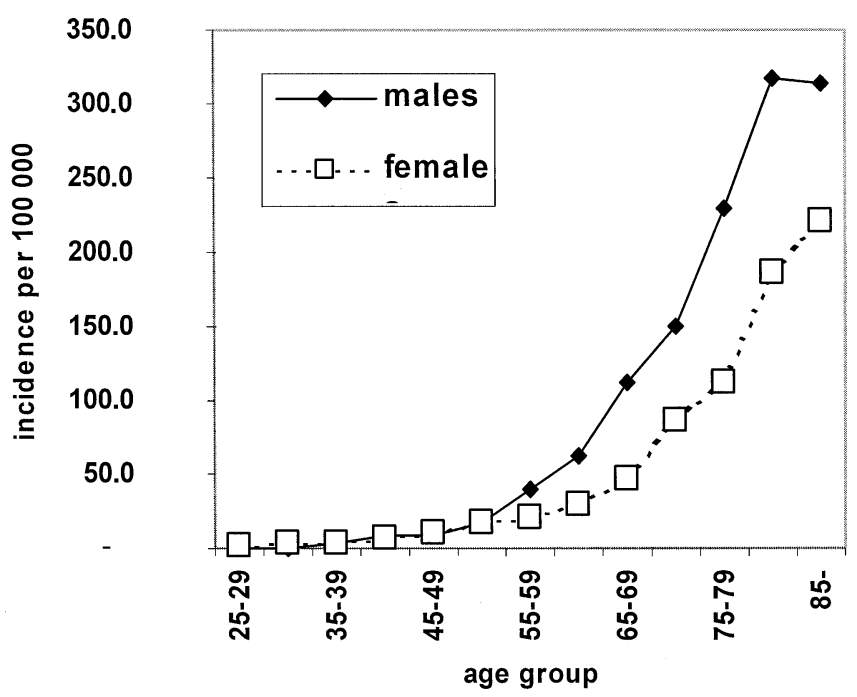

Fig. 5. Annual age-group-specific incidences of gastric cancer among males and females. Data from Finnish Cancer registry in 1986

females before age 60 (Fig. 6). The age-specific M/F ratio rises and is high in young age groups when the appearance and onset of new cases of the intestinal type of GCA is more frequent in males than in females, and decreases in old age groups, in which the appearance and onset of GCA becomes more and more frequent also in females.

Because it is well known that the intestinal type of gastric cancer is the last stage in a series of neoplastic transformations of the inflamed mucosa and $H$. pylori gastritis [2], we also investigated whether there were any sex differences in the prevalence of GCA precursor conditions, i.e., chronic gastritis, gastric atrophy, and intestinal metaplasia. Table 2 presents data on these 

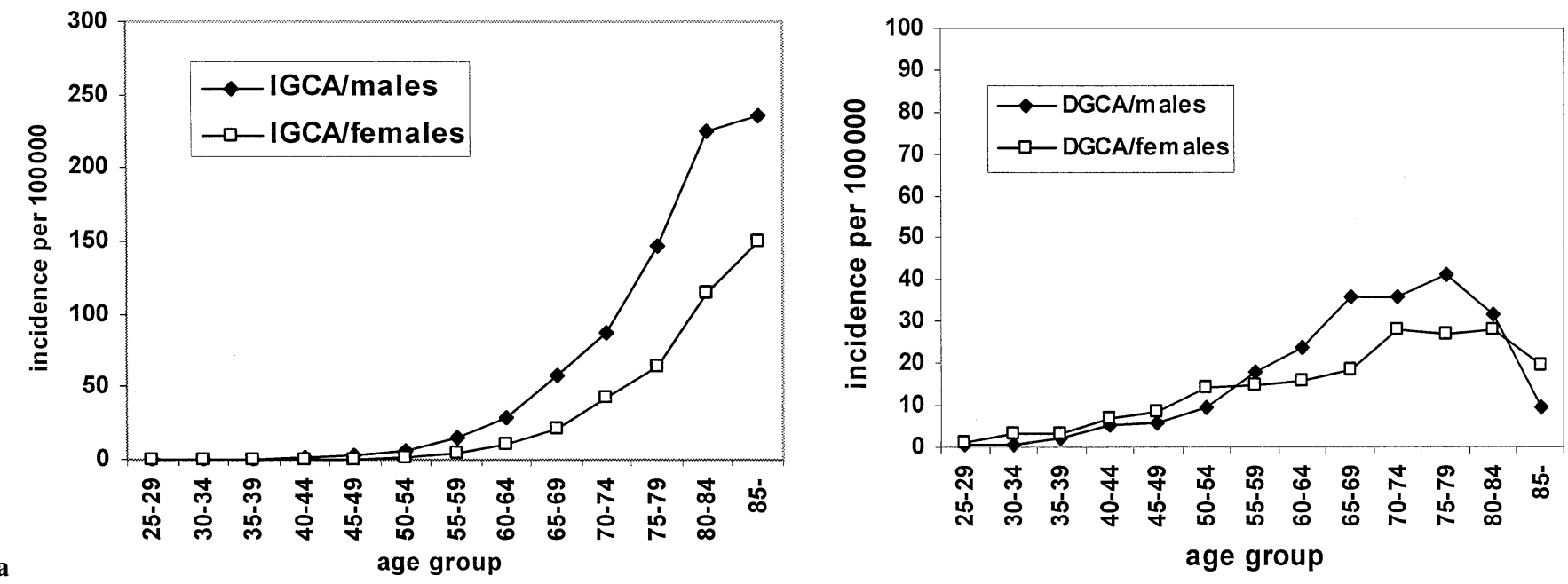

Fig. 6a,b. Annual age-group-specific incidences of gastric cancer of a the intestinal (IGCA) type and $\mathbf{b}$ diffuse $(D G C A)$ type in males and females. The incidences were obtained by calculating the proportions of gastric cancers of the intestinal and diffuse subtypes in 5-year age groups in a consecutive series of 938 gastric cancer patients and by applying these proportions to the gastric cancer incidence data (Finnish Cancer Registry in 1986)

Table 1. Demographics of gastric cancer. A consecutive series of cancers diagnosed by endoscopy, surgery, or autopsy at the Helsinki District University Central Hospital (HUCH)-Jorvi Hospital from 1976-1995

\begin{tabular}{lcccc}
\hline Subtype & $\begin{array}{c}\text { Total } \\
\text { no. }\end{array}$ & $\begin{array}{c}\text { Age (years; } \\
\text { mean } \pm \mathrm{SD})\end{array}$ & $\begin{array}{c}\text { Males, } \\
\text { percent share }\end{array}$ & $\begin{array}{c}\text { Proximal } \\
\text { (angulus or above), } \\
\text { percent share }\end{array}$ \\
\hline Intestinal & 434 & $70 \pm 10$ & $62 \%$ & $60 \%$ \\
Diffuse & 371 & $58 \pm 13$ & $46 \%$ & $71 \%$ \\
Unclassified & 133 & $68 \pm 12$ & $62 \%$ & $66 \%$ \\
Total & 938 & $65 \pm 13$ & $55 \%$ & $65 \%$ \\
\hline
\end{tabular}

Table 2. Prevalence of chronic gastritis, atrophic gastritis of any grade, and advanced (moderate or severe) atrophic gastritis in consecutive outpatients endoscopied in 19861991

\begin{tabular}{lcccc}
\hline & $\begin{array}{c}\text { Total } \\
\text { No. }\end{array}$ & $\begin{array}{c}\text { Chronic gastritis } \\
\text { No. \% }(95 \% \mathrm{CI})\end{array}$ & $\begin{array}{c}\text { Atrophic gastritis } \\
\text { No. \% }(95 \% \mathrm{CI})\end{array}$ & $\begin{array}{c}\text { Advanced } \\
\text { atrophic gastritis } \\
\text { No. \% (95\%CI) }\end{array}$ \\
\hline $\begin{array}{l}\text { Age group 20-49 } \\
\text { Males }\end{array}$ & 431 & $23955 \%(51-60)$ & $4611 \%(8-14)$ & $174 \%(2-6)$ \\
$\begin{array}{l}\text { Females } \\
\text { Age group 50-59 }\end{array}$ & 381 & $13636 \%(31-41)$ & $4913 \%(9-16)$ & $216 \%(3-8)$ \\
$\begin{array}{l}\text { Males } \\
\text { Females }\end{array}$ & 162 & $12778 \%(72-85)$ & $4628 \%(21-35)$ & $1610 \%(5-14)$ \\
$\begin{array}{l}\text { Age group 60-79 } \\
\text { Males }\end{array}$ & 239 & $17774 \%(69-80)$ & $7230 \%(24-36)$ & $3414 \%(10-19)$ \\
Females & 194 & $16686 \%(81-91)$ & $9147 \%(40-54)$ & $5227 \%(21-33)$ \\
\hline
\end{tabular}

$95 \%$ Confidence intervals (95\% CIs) are indicated in parentheses

prevalences in Finland from a survey of a consecutive series of 1700 outpatients endoscopied during 19861991. No sex differences were found after age 50 in the prevalence of gastritis, atrophic gastritis, or intestinal metaplasia. In younger patients (age group, 20-49 years), however, the prevalence of nonatrophic gastritis was slightly higher in males than in females, at $55 \%$ in males and $36 \%$ in females $\left(P<0.05 ; x^{2}\right.$ test $)$. 


\section{Discussion}

This study indicates that the male predominance of GCA is related to a delay in the "timing" of the appearance and onset of GCA of the intestinal type in females relative to males. It opposes the view that the risk of GCA is simply higher in men than women. In fact, it seems that the incidence of GCA increases progressively with age quite equally in both sexes, but that this progression begins 10-15 years earlier in males than in females. Because of the limited lifetime, this difference in "timing" results in a false impression that GCA is, in general, more common in males than in females.

The difference in the timing of the appearance of GCA between the sexes is well demonstrated with the age group-specific $\mathrm{M} / \mathrm{F}$ ratio of GCA incidence. In relation to age, the $\mathrm{M} / \mathrm{F}$ ratio forms a curve with a "lowhigh-low" pattern in which the peak is reached at the age of 60 years. This age point seems to indicate an age period during which the rise of the annual GCA incidence in females proportionally exceeds that in males. A surprising finding is that this "peak" of the $\mathrm{M} / \mathrm{F}$ curve is always at age 60 , in all countries from which reliable statistics on GCA incidence are available. The "lowhigh-low" pattern of the $\mathrm{M} / \mathrm{F}$ ratio has also remained unchanged over the decades, from the 1950s, in Finland, even though the incidence of gastric cancer has markedly decreased in both sexes, by approximately $70 \%$ [4]. The "low-high-low" pattern also seems to be similar all over the world, being unrelated to the incidence of the GCA, ethnicity, or socioeconomics, and is similar in all birth cohorts.

This globality and consistency of the age-specific pattern of the $\mathrm{M} / \mathrm{F}$ curve firmly suggests some globality and consistency in the pathogenesis of GCA in general; i.e., the pathogenesis of GCA must include similar intrinsic mechanisms all over the world, even though the incidence varies a lot. The global consistency of the $\mathrm{M} / \mathrm{F}$ pattern suggests, further, that the differences in the pathogenesis of GCA between males and females are based on some basic biological differences between the sexes, rather than being simply a result of environmental factors alone. In this respect, two options are conceivable. First, male sex is somehow linked to an inherent susceptibility to gastric cancer, or, alternatively, female sex, i.e., female hormones, are protective. The second option (or possibility) is that sex differences interact with environmental influences, and this determines the risk. In this respect, the characteristics of $H$. pylori infection are to be considered in particular, because this infection is the main cause of chronic gastritis, the forerunner of gastric cancer in most of the cases.

The present results exclude neither of the above two possibilities. The hormonal hypothesis is supported by the present observation that females seem to be "pro- tected" from GCA of the intestinal type up to menopausal age, after which the GCA incidence begins to increase among the women as well. After the menopause, this increase is similar to that in males, or it may even occur more rapidly, as evidenced by a decrease in the $\mathrm{M} / \mathrm{F}$ ratio pattern in old age. This inevitably raises the hypothesis that female sex hormones, i.e., estrogens, have a potency to prevent or inhibit the genesis of GCA of the intestinal type.

The dependence of gastric carcinoma on sex hormones was suggested in some earlier studies. In a case-control study of 339 postmenopausal women with gastric cancer, Palli et al. [6] did find an inverse relation of GCA risk with the duration of fertility and lateness of the menopause. This was indicated to suggest that female hormones have a protective influence against stomach cancer.

The male predominance of GCA is also seen in laboratory animals [7]. Experimental gastric cancer is more frequently and more easily induced in male than in female animals. Castration and supplementation with estrogens lower the rate of experimental cancer, and a high cancer rate can again be achieved by stopping the application of estrogens, or by giving male sex hormones. Large epidemiological studies have further indicated that postmenopausal hormonal replacement therapy (HRT) lowers the overall rate of nongynecological cancer, including gastrointestinal cancers, colonic cancers in particular [8-12]. Correspondingly, it could be anticipated that HRT could also protect women from GCA, especially GCA of the intestinal type.

Estrogen receptors have been shown to occur in gastric epithelial cells [13-17]. In the gastrointestinal tract, including stomach, estrogens stimulate the expression of cysteine-rich trefoil peptides [18-23], which are expressed in mucin-producing cells and play a protective role in maintaining the integrity of the gastrointestinal mucosa and regulate the cell cycle, and may act as tumor suppressors [19-23].

H. pylori gastritis and atrophic gastritis are premalignant conditions, which raise the risk and initiate the pathogenesis of GCA [2]. H. pylori infection occurs in about $80 \%-90 \%$ of GCA patients in the Western world and has to be, therefore, considered as a potential factor causing the differences in GCA between the sexes. $H$. pylori infection and gastritis are reported to occur equally often in both sexes, and this equality also seems to be the case concerning the occurrence of atrophic gastritis and intestinal metaplasia in males and females in the present survey.

A possibility, however, is that the timing (age) at the acquisition of the $H$. pylori infection also plays a role in the timing of the appearance of GCA of the intestinal type in old age [24]. This implies that boys may get $H$. 
pylori gastritis at a younger age than girls; i.e., boys are infected earlier than girls in the same birth cohort. In the present study (Finland), the males in the youngest age group (20-49 years) had a higher prevalence of $H$. pylori gastritis than the females.

Some other studies have also reported a slight excess of nonatrophic gastritis in young males. In Nariño [25], a high-risk area for GCA in Colombian, $23.5 \%$ of men in the age group 25 to 44 years had $H$. pylori nonatrophic gastritis compared with $13.6 \%$ of females. Klein and co-workers [26] described the natural history of the infection in Peruvian children aged 6 to 30 months. The overall prevalence of the infection in infancy decreased from $71.4 \%$ to $47.9 \%$, and a significant sex difference was found: boys, reduction from $63.6 \%$ to $55 \%$; girls, reduction from $80 \%$ to $38.7 \%(P=$ $0.03)$. They concluded that, 18 months after birth, boys were more likely to acquire and less likely to clear the H. pylori infection than girls. In a community with a very high GCA risk in the Colombian Andes (Aldana, Nariño), boys from 3 to 9 years of age had a higher prevalence of the infection than girls: $76.7 \%$ vs $65.8 \%$ $(P=0.015)$ [27].

In a biracial rural community in Louisiana, in which gastric cancer rates in blacks are more than double those in whites, Malaty et al. [28] reported that, over a period of 12 years, $50 \%$ of white children lost their $H$. pylori infection, compared with only $4 \%$ of black children. The prevalence of infection was greater in boys than in girls. In addition, spontaneous elimination of the helicobacter infection from children has also been reported previously in developed countries [29,30]. No sex differences in those low-risk populations have been reported.

The age at first infection determines the length of time in which the infection has persisted as chronic gastritis. According to some views [24], an earlier age of $H$. pylori acquisition could result in earlier "timing" of the appearance of GCA in males compared with females. The situation has some similarities to the relationship between smoking and lung cancer. Doll and Peto [31] have estimated that a $10 \%$ excess prevalence of smoking around age 20 could lead to doubling of the rates of lung cancer around age 60 . This may reflect carcinogenic forces produced by the constant inflammation of the bronchial mucosa which accumulates over decades of smoking. Doll and Peto [31] have further proposed mathematical formulas in which the time of exposure has the greatest influence on the outcome. The chronic inflammation of the gastric mucosa elicited by infection with $H$. pylori may exert a similar carcinogenic influence which can be accumulated over the years. In both mucosas, bronchial and gastric, sequential precancerous lesions have been identified.

\section{References}

1. Parkin DM, Muir CS, Whelan YT, Gao J, Ferlay J, Powell J. Cancer in five continents. Vol VI. IARC Scientific Publication No. 120. Lyon: IARC; 1992.

2. Schistosomes, liver flukes and Helicobacter pylori. In: IARC monographs on the evaluation of carcinogenic risks to humans. Volume 61. Lyon: IARC; 1994. pp 177-220.

3. Finnish Cancer Registry. Cancer incidence in Finland 1986. Helsinki: Cancer Society of Finland publication 46; 1990.

4. Hakulinen T, Andersen AA, Malker B, Pukkala E, Schou G, Tulinius H. Trends in cancer incidence in the Nordic Countries. Acta Pathol Microbiol Scand Sect A 1986;94(Suppl 288):1151.

5. Laurén P. The two histological main types of gastric carcinoma: diffuse and so-called intestinal type carcinoma. Acta Pathol Microbiol Scand Sect A 1965;64:31-49.

6. Palli D, Cipriani F, Decarli A, Galli M, Saieva C, Fraumeni JF, et al. Reproductive history and gastric cancer among postmenopausal women. Int J Cancer 1994;56:812-5.

7. Furukawa H, Iwanaga T, Koyama H, Taniguchi H. Effect of sex hormones on the experimental induction of cancer in rat stomach-a preliminary study. Digestion 1982;23:151-5.

8. Ando Y, Watanabe H, Fujimoto N, Ito A, Toge T. Progesterone enhancement of stomach tumor development in SD rats treated with N-methyl-N-nitro-N-nitrosoguanidine. Jpn J Cancer Res 1995;86:924-8.

9. Campbell-Thompson M, Lauwres GY, Reyher KK, Cromwell J, Shiverick KT. 17 Beta-estradiol modulates gastroduodenal preneoplastic alterations in rats exposed to the carcinogen $\mathrm{N}$ methyl-N'-nitro-nitrosoguanidine. Endocrinology 1999;140:4886494.

10. Newcomb PA, Storer BE. Postmenopausal hormone use and risk of large-bowel cancer. J Natl Cancer Inst 1995;87:106771.

11. Nanda K, Bastian LA, Hasselblad V, Simel DL. Hormone replacement therapy and the risk of colorectal cancer: a metaanalysis. Obstet Gynecol 1999;93:880-8.

12. Pukkala E, Tulenheimo-Silfvast A, Leminen A. Incidence of cancer among women using long versus monthly cycle hormonal replacement therapy, Finland 1994-1997. Cancer Causes Control 2001;12:111-5.

13. Kojima O, Takahashi T, Kawakami S, Uehara Y, Matsui M. Localization of estrogen receptors in gastric cancer using immunohistochemical staining of monoclonal antibody. Cancer 1990; 67:2401-6.

14. Sica V, Nola E, Contieri E, Bova R, Masucci MT, Medici N, et al. Estradiol and progesterone receptors in malignant gastrointestinal tumors. Cancer Res 1984:44:4670-4.

15. Tokunaga A, Nishi K, Matsukura N, Tanaka N, Onda M, Shirota $\mathrm{A}$, et al. Estrogen and progesterone receptors in gastric cancer. Cancer 1986;57:1376-9.

16. Wu CW, Chi CW, Chang TJ, Lui WY, Peng FK. Sex-hormone receptors in gastric cancer 1990;65:1396-400.

17. Harrison JD, Jones JA, Ellis IO, Morris DL. Oestrogen receptor D5 antibody is an independent negative prognostic factor in gastric cancer. Br J Surg 1991;78:334-6.

18. Campbell-Thompson ML. Estrogen receptor alpha and beta expression in upper gastrointestinal tract with regulation of trefoil factor family 2 mRNA levels in ovariectomized rats. Biochem Biophys Res Commun 1997;240:478-83.

19. Lefebvre O, Chenard MP, Masson R, Linaris J, Dierich A, LeMeur $\mathrm{M}$, et al. Gastric mucosa abnormalities and tumorigenesis in mice lacking the sP2 trefoil protein. Science 1996; 274:259-61.

20. Wong WM, Poulsom R, Wright NA. Trefoil peptides. Gut 1999; 44:890-5.

21. Luqmani Y, Bennett C, Paterson I, Corbishley CM, Rio M-C, Chambon P, Ryall G. Expression of the $p S 2$ gene in normal, 
benign and neoplastic human stomach. Int J Cancer 1989;44:80612.

22. Calnan DP, Westley BR, May FE, Floyd DN, Marchbank T, Playford RJ. The trefoil peptide TFF1 inhibits the growth of the human gastric adenocarcinoma cell line AGS. J Pathol 1999;188: $312-7$.

23. Leung WK, Yu J, Chan FK, To KF, Chan MW, Ebert MP, et al. Expression of trefoil peptides (TFF1, TFF2, and TFF3) in gastric carcinomas, intestinal metaplasia, and non-neoplastic gastric tissues. J Pathol 2002;197:582-8.

24. Blaser MJ, Chyou PH, Nomura A. Age at establishment of Helicobacter pylori infection and gastric carcinoma, gastric ulcer, and duodenal ulcer risk. Cancer Res 1995;53:562-5.

25. Correa P, Cuello C, Duque E, Burbano LC, Garcia FT, Bolanos $\mathrm{O}$, et al. Gastric cancer in Colombia. III. Natural history of precursor lesions. J Natl Cancer Inst 1976;57:1027-35.

26. Klein PD, Gilman RH, Leon-Barua R, Diaz F, Smith EO, Graham DY. The epidemiology of Helicobacter pylori in Peru- vian children between 6 and 30 months of age. Am J Gastroenterol 1994;89:2196-200.

27. Goodman KJ, Correa P. Transmission of Helicobacter pylori among siblings. Lancet 2000;355:358-62.

28. Malaty HM, Graham DY, Wattigney WA, Srinivasan SR, Osato M, Berenson GS. Natural history of Helicobacter pylori infection in childhood: 12-year follow-up cohort study in a biracial community. Clin Infect Dis 1999;28:279-82.

29. Ashorn M, Mäki M, Hällström M, Uhari M, Åkerblom HK, Viikari J, Miettinen A. Helicobacter pylori infection in Finnish children and adolescents. A serologic cross-sectional and followup study. Scand J Gastroenterol 1995;30:876-9.

30. Granström M, Tindberg Y, Blennow M. Seroepidemiology of Helicobacter pylori infection in a cohort of children monitored from 6 months to 11 years of age. J Clin Microbiol 1997;35:468-70.

31. Doll R, Peto R. Cigarette smoking and bronchial carcinoma: dose and time relationship between regular smokers and lifelong nonsmokers. J Epidemiol Community Health 1978;32:303-13. 